\title{
Effect of Softer Flooring in Tie Stalls on Resting Behavior and Leg Injuries of Lactating Cows
}

\author{
J. Rushen, ${ }^{* 1}$ D. Haley, $†$ and A. M. de Passillé* \\ *Pacific Agri-Food Research Centre, Agriculture and Agri-Food Canada, PO Box 1000, 6947 Highway 7, Agassiz, British Columbia, \\ VoM 1A0, Canada \\ †Alberta Agriculture, Food and Rural Development, \#301, 4920-51 Street, Red Deer, Alberta, T4N 6K8, Canada
}

\begin{abstract}
To test the advantages of softer flooring in tie stalls, we compared the behavior and injuries of dairy cows housed in tie stalls with either soft rubber mats ( $\mathrm{n}=$ 12 ) or concrete flooring ( $\mathrm{n}=12$ ), both lightly covered with straw. Data were collected for $112 \mathrm{~d}$ beginning at 14 DIM ( $\pm 4 \mathrm{~d})$. Cows' general activity was observed continuously for $24 \mathrm{~h}$ every $28 \mathrm{~d}$. Behavior was also scored by a scan sampling technique every $14 \mathrm{~d}$ such that each cow was observed for a period of 3 min every $12 \mathrm{~min}$. We scored the occurrence of leg lesions and other injuries every $7 \mathrm{~d}$ throughout the study. Cows on rubber mats had shorter bouts of lying but the frequency of bouts was higher, leading them to tend to spend more time lying compared with cows housed on concrete. Cows on concrete spent more time standing idle, but there was no difference in the time spent eating. There was no effect of stall flooring on the number of minor abrasions to the legs and body. There was a significantly higher incidence of swelling of the carpus joints for cows housed on concrete. Cows housed on soft rubber flooring appeared to be less hesitant to change posture from lying to standing (and vice versa), and as a result changed posture more frequently and spent more time lying than cows on concrete flooring. The decreased incidence of swelling of the carpus joint for cows on soft rubber mats may have important longterm effects in preventing a variety of leg problems.
\end{abstract}

Key words: dairy cow, comfort, stall design, welfare

\section{INTRODUCTION}

Today's high-performing dairy cows need adequate rest and a comfortable environment to maximize their production and ensure their well-being. High-producing dairy cows spend about 40 to $60 \%$ of the day lying, and disturbed rest may increase the risk of lameness

Received July 21, 2006.

Accepted April 26, 2007.

${ }^{1}$ Corresponding author: rushenj@agr.gc.ca and result in physiological changes that are likely to affect health and milk production (Munksgaard et al., 1999; Fisher et al., 2002). Cattle that are prevented from lying down show an increased motivation to lie down and will even give up feed to do so (Jensen et al., 2005). It is clear that to maintain high levels of production and good welfare, it is essential that lactating dairy cows be able to optimize their time spent resting. Resting time is reduced when cows are housed in poorly designed stalls, especially where flooring is too hard. Because of concern about mastitis, there is reduced use of organic bedding for dairy cattle (e.g., Elbers et al., 1998), which may result in cows being kept on concrete floors. Recently, there has been considerable development in improved flooring types for stalls, with an emphasis on the development of rubberbased floors that are soft.

Most of the research on stall design has focused on free stalls and has shown that cattle prefer to lie on softer surfaces and will lie for longer periods each day in cubicles with softer flooring (e.g., Manninen et al., 2002; Tucker et al., 2003; Drissler et al., 2005). Inappropriate flooring can also increase the risk of injury, especially to the hocks (Weary and Taszkun, 2000). Less research has examined the comfort of tie stalls, even though this remains a common way of housing dairy cattle (Zurbrigg et al., 2005a,b). Haley et al. (2001) found that bare concrete floors in tie stalls reduced lying time by $1.8 \mathrm{~h} / \mathrm{d}$ compared with geotextile mattresses. Many cows in commercial tie stalls show lesions to the hock or neck, which may be related to the design of the tie stall (Zurbrigg et al., 2005a,b), and use of bare concrete floors in tie stalls increases the risk of sole hemorrhages (Bergsten and Frank, 1996).

In the following study, we compared daily activity patterns of cows kept for several weeks in tie stalls that differed in the softness of the flooring. We examined the effects on resting and feeding behavior and the incidence of injuries to the legs. We also looked at the correlation between cow behavior and the incidence of injuries. 
Table 1. Age, parity, BW, DIM, and previous milk production of cows prior to entry into stalls with either concrete floor or NRI mats ${ }^{1}$

\begin{tabular}{lcr}
\hline Item & Concrete & \multicolumn{1}{c}{ NRI mats $^{2}$} \\
\hline Age (mo) & $49.0 \pm 11.3(35-74)$ & $50.7 \pm 10.8(39-71)$ \\
Parity (lactation no.) & $2.9 \pm 0.9(2-5)$ & $2.8 \pm 0.9(2-4)$ \\
Milk production in previous lactation (kg) & $7,847 \pm 786(6,975-9,558)$ & $7,963 \pm 1,294(6,415-10,443)$ \\
DIM & $14.0 \pm 4.6(11-26)$ & $13.3 \pm 4.1(10-24)$ \\
BW (kg) & $624.5 \pm 70.8(531-711)$ & $619.0 \pm 59.3(532-706)$ \\
\hline &
\end{tabular}

\section{MATERIALS AND METHODS}

\section{Animals and Housing}

All experimental practices were approved by the local Institutional Animal Care Committee of the Lennoxville Research Center of Agriculture and Agri-Food Canada, which complies with the guidelines of the Canadian Council on Animal Care.

Twenty-four late-gestation multiparous Holstein cows were purchased from local producers and housed in tie stalls. Within the barn there were 2 rows of stalls facing each other. One row of stalls $(n=12)$ was 1.80 $\mathrm{m}$ (length) $\times 1.30 \mathrm{~m}$ (width) and had conventional closed tie-stall fronts (Comfort H-500, J. Houle and Sons Inc., Drummondville, Quebec, Canada). The other row of stalls $(\mathrm{n}=12)$ were slightly longer $(1.95 \mathrm{~m}$ length $\times 1.30$ $\mathrm{m}$ width) and had open stall fronts (Comfort Plus $\mathrm{H}$ 1100, J. Houle and Sons Inc.). The stalls were described previously in Haley et al. (2001). The barn was artificially ventilated, with lights on from 0600 to $2200 \mathrm{~h}$. A TMR was fed to individual ad libitum intake. Fresh feed was delivered once daily $(1400 \mathrm{~h})$. Water was drunk from float-activated water bowls shared by adjacent cows, and bowls were cleaned every 2 wk. Cows were milked twice daily (0600 and $1800 \mathrm{~h}$ ).

\section{Treatments}

Approximately $14 \mathrm{~d}$ (range 10 to $26 \mathrm{~d}$; see Table 1 ) after calving, the cows were moved from the calving pens into tie stalls with either single-layer rubber mats specially designed to provide extra softness (Cloud 9, NRI Industries, Toronto, Ontario, Canada) or concrete flooring. Pairs of stalls with each type of flooring were alternated within the 2 rows of tie stalls. All stalls were freshly bedded each day with an equal amount of chopped straw $(0.5 \mathrm{~kg})$. The age, parity, stage of lactation at the start of the study, and previous milk production of the cows in the 2 groups are shown in Table 1.

\section{Behavioral Observations}

Cows were videotaped for $24 \mathrm{~h}$ every 2 wk during the 16 -wk study. Time-lapse video recorders were used in 24-h time mode to record output from 4 cameras with a video multiplexer system. Videotapes were read by using a time-sampling technique such that each cow was watched for a 3-min period every $12 \mathrm{~min}$ (i.e., 5 samples/h for a total of $15 \mathrm{~min} / \mathrm{h}$ ). At the beginning of the 3-min observation window, we recorded whether cows were standing or lying. If cows were standing, we noted whether the cows were eating or standing idle. If the cow was lying, we recorded whether the head was upright (i.e., supported by the neck) or resting on the ground or on the cow's back. The video recordings of each animal during wk $1,4,8,12$, and 16 were also read continuously to get a more precise estimate of the duration and frequency of bouts of lying down and standing.

\section{Injury Scoring}

All cows were examined for any injuries within $24 \mathrm{~h}$ of starting the 16 -wk trial. The total number of separate injuries (cuts, abrasions, or patches of hair loss) was subsequently recorded one day each week beginning the week of the first day that the cows were placed in the tie stalls. In addition, we estimated the occurrence of swelling of the knees and the hocks once a week. This was done by a single trained observer who palpated each joint by hand and scored each of the 4 joints for the presence (0) or absence (1) of noticeable swelling.

\section{Statistical Analysis}

Two cows (one from each type of flooring) were removed from the study because of chronic mastitis. Their data are not included in the analyses.

The behavioral data were analyzed using PROC MIXED of SAS (SAS Inst. Inc., Cary, NC), with cow as a random factor, treatment as a main factor, week as a repeated measure, and interactions between week and treatment. The effect of treatment was tested by using cow nested within treatment as an error term. Preliminary analysis revealed a positive skew in much of the behavioral data, so the analysis was done by using a log transformation (which removed the positive 
Table 2. Results of statistical analysis showing effect of treatment (type of stall floor covering) and interaction between treatment and period and mean values (averaged over $16 \mathrm{wk}$ ) for behavioral observations for cows kept in tie stalls with either concrete floors or rubber mats.

\begin{tabular}{|c|c|c|c|c|c|}
\hline Behavior & Treatment $^{1}$ & $\begin{array}{l}\text { Treatment } \\
\times \text { period }^{1}\end{array}$ & Concrete $^{2}$ & $\begin{array}{c}\text { Rubber } \\
\text { mat }^{2}\end{array}$ & $\mathrm{SE}^{2}$ \\
\hline \multicolumn{6}{|l|}{ Lying down } \\
\hline Total duration $(\mathrm{h})$ & 0.051 & $>0.10$ & 8.13 & 9.37 & 0.29 \\
\hline Bout frequency & 0.01 & $>0.10$ & 6.23 & 9.62 & 0.42 \\
\hline Mean bout duration (min) & 0.07 & $>0.10$ & 78.29 & 58.44 & 19.50 \\
\hline \multicolumn{6}{|l|}{ Standing } \\
\hline Total duration $(\mathrm{h})$ & 0.04 & $>0.10$ & 14.98 & 13.67 & 0.29 \\
\hline Mean bout duration (min) & 0.02 & $>0.10$ & 118.23 & 76.58 & 12.31 \\
\hline \multicolumn{6}{|l|}{ Head position when lying } \\
\hline On back (\% of observations ${ }^{3}$ ) & $>0.10$ & $>0.10$ & 4.04 & 3.54 & 0.58 \\
\hline On ground ( $\%$ of observations ${ }^{3}$ ) & $>0.10$ & $>0.10$ & 3.67 & 1.71 & 2.21 \\
\hline Head up $\left(\%\right.$ of observations $\left.{ }^{3}\right)$ & 0.03 & $>0.10$ & 28.71 & 33.38 & 6.30 \\
\hline Standing idle (\% of observations ${ }^{3}$ ) & 0.03 & $>0.10$ & 40.96 & 34.92 & 1.04 \\
\hline Standing feeding (\% of observations ${ }^{3}$ ) & $>0.10$ & $>0.10$ & 21.42 & 21.75 & 0.33 \\
\hline
\end{tabular}

${ }^{1}$ Probability values based on mixed models for all variables.

${ }^{2}$ Mean and SE values based on least squares means.

${ }^{3}$ Based on the percentage of total observations.

skew in the data) and an arcsine transformation (to remove the effect of proportional data). However, these transformations did not affect the pattern of significance, so here we report the results from untransformed data. Because the distribution of injury scores remained nonnormal even after transformation, Wilcoxon tests were used to test differences between type of stall flooring on injury scores (number of cuts per animal summed over all weeks) and the total incidence of swelling on the front knees and hocks (based on the number of legs that showed some sign of swelling multiplied by the number of weeks on which this was observed). Results are presented as mean and standard error. A Pearson correlation was calculated between the total incidence of swelling of the front knees and the mean duration per day of lying.

\section{RESULTS}

\section{Lying and Standing}

Table 2 shows the results of the statistical analysis for the behavioral data. Cows on the rubber mats spent less time standing and tended to spend more time lying than cows on concrete. The reduction in time spent lying on concrete was due to a reduction in the frequency of bouts of lying down. The cows on concrete floors had longer mean bout durations of standing and tended to have longer mean bout durations of lying than cows on rubber mats. The increased lying time was spent with the head up; there was no difference in the time spent with the head on the back or with the head on the ground. The reduction in time spent standing on rubber mats was due to a reduction in the amount of time spent standing idle, but there was no change in the time spent feeding. There was no significant interaction between time period and treatment for any variable.

\section{Injuries}

There were no significant differences between the 2 types of flooring on the occurrence of minor injuries either to the legs or to the body $(P>0.10)$. The incidence of swollen knees and hocks tended to be lower for cows kept on rubber mats than on concrete $(P=0.06)$. When swellings were divided into front knees and hocks, the differences between rubber mats and concrete were significant for the front knees (concrete $0.32 \pm 0.09$; rubber mats $0.11 \pm 0.04 ; P=0.049)$ but not for the hocks $(P>$ $0.10)$. There was a moderate correlation $(\mathrm{r}=-0.52 ; P=$ 0.01 ) across cows between the occurrence of swelling on the front knees and the total duration of time spent lying.

\section{DISCUSSION}

Our results showed that cows kept in tie stalls with hard concrete floors spend more time per day standing without feeding and tended to spend less time lying. Feeding time was not affected. The reduction in lying time was due primarily to a reduction in the frequency of lying bouts: the mean duration of bouts of both lying and standing were actually higher on the concrete floors than on the rubber floors. Thus, the main effect of the softer flooring was to increase the willingness of the cows to change posture, that is, to lie down and to stand up. Once the cows were lying down or standing, they continued to lie or stand for a shorter period of time on the softer flooring. The current results confirm those of Haley et al. (2001), who found a similar pattern over a 
shorter period of time. The present results suggest that cattle did not adapt to the harder floors, at least over the first $16 \mathrm{wk}$ of lactation. These results confirm findings for free stalls, in which soft stall floors have been shown to increase lying time and stall acceptability (Tucker et al., 2003; Wagner-Storch et al., 2003; Fulwider and Palmer 2004).

Cows in comfortable surroundings typically lie down between 9 and $13 \mathrm{~h} / \mathrm{d}$ (Tucker et al., 2003; Cook et al., 2004a,b; Drissler et al., 2005). In the current study, cows in stalls with rubber mats fell within this range; however, those on concrete lay down for $1.2 \mathrm{~h}$ less and below the range normally observed. Whether the reduction in lying time is sufficient to affect the welfare of cattle is hard to say. Changes in activity of the the hypothalamic-pituitary-adrenocortical axis as a result of lying deprivation are typically reported when lying time is reduced by 4 to $6 \mathrm{~h} / \mathrm{d}$ (Munksgaard et al., 1999; Fisher et al., 2002). Increased time spent standing on hard surfaces has been implicated as a risk factor for lameness (Cook et al., 2004b). Although lameness is typically less prevalent in cows in tie stalls than in free stalls, it does occur. Our results suggest that concrete flooring in tie stalls may increase the risk of lameness because it increases the time spent standing on a hard surface.

The mean bout durations of lying (50 to $120 \mathrm{~min}$ ) were in the ranges reported previously for cows in free stalls (Tucker et al., 2003; Cook et al., 2004a; Drissler et al., 2005) and tie stalls (Haley et al., 2001). However, the number of lying bouts was smaller than the 11 to 12/d reported for free stalls (Cook et al., 2004a; Drissler et al., 2005) and for tie stalls (Haley et al., 2001). In contrast, Tucker et al. (2003) reported similar effects of hard and soft flooring in free stalls on the number of bouts of lying down.

The increased lying time on the rubber floors was spent mainly in lying with the head up. There were no differences between the floor types in the time cows spent lying with their heads resting on the ground or on the back. Results of electroencephalography observations on calves (Hänninen et al. 2002) suggest that most actual sleep in cattle occurs when the head is resting on the ground or on the back. If we can extrapolate these findings to adult cattle, it suggests that the type of flooring did not influence the amount of sleep itself, but rather the amount of time that the cattle rest without sleeping. We estimated that the cows spent on average 1.5 to $2 \mathrm{~h} / \mathrm{d}$ lying down with their heads resting either on their backs or on the ground. This is considerably less than the $4 \mathrm{~h} / \mathrm{d}$ that Ruckebusch (1974) estimated as the amount of time that adult cows sleep. Thus, it seems likely that some degree of sleep may have occurred while the cows were resting with their heads up. Therefore, we clearly need further research with electrophysiological techniques to identify the phases of sleep in adult cattle to determine whether stall design affects actual sleep.

The mean feeding time of $5 \mathrm{~h} / \mathrm{d}$ corresponds to that previously reported in free stalls (Cook et al., 2004a). There was no difference between the types of stall floors in the amount of time spent feeding. Instead, the extra time cows spent standing on the concrete floors was spent idle.

Cows kept in tie stalls frequently have minor cuts on the bodies and legs (Zurbrigg et al., 2005a,b). There was no difference between cows kept on rubber floors and cows kept on concrete floors, which suggests that the stall flooring is not responsible for the incidence of cuts. These injuries may result more from collisions with the bars of the stall as the cow lies down (Zurbrigg et al., 2005a,b). In contrast, there was a greater incidence of swelling of the front knees among the cows kept on concrete floors. Furthermore, there was a moderate negative correlation between the occurrence of swelling and the amount of time the cows were lying down. When cows lie down and stand up, they place much of their weight on their front knees (Lidfors, 1989); therefore, the increased swelling of the front knees would make the act of lying down painful, which could explain the reduced frequency of bouts of lying down. The results shed some light on the mechanisms by which uncomfortable flooring in the stall reduces the time spent lying down. We suggest that the hard floors lead to increased swelling (and presumably soreness of the front knees), which leads to a reduced willingness of the cow both to lie down and to stand up.

\section{ACKNOWLEDGMENTS}

Funding was provided by NRI Inc. and Agriculture and Agri-Food Canada MII funds. We thank Marjolaine St-Louis, Isabelle Blanchet, Keith Carter, and the staff of the Lennoxville Dairy Centre for invaluable help.

\section{REFERENCES}

Bergsten, C., and B. Frank. 1996. Sole haemorrhages in tied primiparous cows as an indicator of periparturient laminitis: Effects of diet, flooring and season. Acta Vet. Scand. 37:383-394.

Cook, N. B., T. B. Bennett, and K. V. Nordlund. 2004a. Effect of free stall surface on daily activity patterns in dairy cows with relevance to lameness prevalence. J. Dairy Sci. 87:2912-2922.

Cook, N. B., K. V. Nordlund, and G. R. Oetzel. 2004b. Environmental influences on claw horn lesions associated with laminitis and subacute ruminal acidosis in dairy cows. J. Dairy Sci. 87(E. Suppl.):E36-E46.

Drissler, M., M. Gaworski, C. B. Tucker, and D. M. Weary. 2005. Freestall maintenance: Effects on lying behavior of dairy cattle. J. Dairy Sci. 88:2381-2387.

Elbers, A. R. W., J. D. Miltenburg, D. De Lange, A. P. P. Crauwels, H. W. Barkema, and Y. H. Schukken. 1998. Risk factors for clinical 
mastitis in a random sample of dairy herds from the southern part of The Netherlands. J. Dairy Sci. 81:420-426.

Fisher, A. D., G. A. Verkerk, C. J. Morrow, and L. R. Matthews. 2002. The effects of feed restriction and lying deprivation on pituitaryadrenal axis regulation in lactating cows. Livest. Prod. Sci. 73:255-263.

Fulwider, W. K., and R. W. Palmer. 2004. Use of impact testing to predict softness, cow preference, and hardening over time of stall bases. J. Dairy Sci. 87:3080-3088.

Haley, D. B., A. M. de Passillé, and J. Rushen. 2001. Assessing cow comfort: Effects of two floor types and two tie stall designs on the behaviour of lactating dairy cows. Appl. Anim. Behav. Sci. 71:105-117.

Hänninen, L., J. Mäkelä, A. M. de Passillé, J. Rushen, and H. Saloniemi. 2002. How does EEG correlate to calves' resting postures? Presentation at the 36th Int. Conf. Int. Soc. Appl. Ethol., Egmond an Zee, the Netherlands.

Jensen, M. B., L. J. Pedersen, and L. Munksgaard. 2005. The effect of reward duration on demand functions of rest in dairy heifers and lying requirements as measured by demand functions. Appl. Anim. Behav. Sci. 90:207-217.

Lidfors, L. 1989. The use of getting up and lying down movements in the evaluation of cattle environments. Vet. Res. Commun. 13:307-324.
Manninen, E., A. M. de Passillé, J. Rushen, M. Norring, and H. Saloniemi. 2002. Preferences of dairy cows kept in unheated buildings for different kinds of cubicle flooring. Appl. Anim. Behav. Sci. 75:281-292.

Munksgaard, L., K. L. Ingvartsen, L. J. Pedersen, and V. K. Nielsen. 1999. Deprivation of lying down affects behaviour and pituitaryadrenal axis responses in young bulls. Acta Agric. Scand. A, Anim. Sci. 49:172-178.

Ruckebusch, Y. 1974. Sleep deprivation in cattle. Brain Res. 78:495-499.

Tucker, C. B., D. M. Weary, and D. Fraser. 2003. Effects of three types of free-stall surfaces on preferences and stall usage by dairy cows. J. Dairy Sci. 86:521-529.

Wagner-Storch, A. M., R. W. Palmer, and D. W. Kammel. 2003. Factors affecting stall use for different freestall bases. J. Dairy Sci. $86: 2253-2266$.

Weary, D. M., and I. Taszkun. 2000. Hock lesions and free-stall design. J. Dairy Sci. 83:697-702.

Zurbrigg, K., D. Kelton, N. Anderson, and S. Millman. 2005a. Stall dimensions and the prevalence of lameness, injury, and cleanliness on 317 tie-stall dairy farms in Ontario. Can. Vet. J. 46:902-909.

Zurbrigg, K., D. Kelton, N. Anderson, and S. Millman. 2005b. Tie-stall design and its relationship to lameness, injury, and cleanliness on 317 Ontario dairy farms. J. Dairy Sci. 88:3201-3210. 